\title{
Knowledge, Attitude and Practice (KAP) about Insecticide Treated Net (ITN) usage against Malaria in Kolla Tembien district, Tigray, Ethiopia
}

\section{Zewdneh Tomass", Tadesse Dejene and Dawit Kidane}

Department of Biology, College of Natural and Computational Sciences, P.O. Box 3072, Mekelle University, Mekelle, Tigray, Ethiopia (*tom_zewde@yahoo.com)

\begin{abstract}
Optimal use of insecticide treated nets (ITNs) to prevent malaria in a community depends on vector behavior, mass distribution, knowledge and willingness of people to use the nets. This study was aimed at evaluating knowledge, attitude and practice (KAP) about ITNs at household level in rural sub-distracts of Kolla Tembien. For this purpose, interview questionnaire containing KAP variables were administered to the randomly selected household heads. A total of 368 households were surveyed, and $70.10 \%$ of the respondents were females. The $\bar{X}$ number of occupants in the households surveyed was found to be 5.50 . However, the $\bar{X}$ number of ITNs owned by the households was found to be 1.07 . Most of the respondents $(82.34 \%)$ indicated ITNs prevent malaria through protection from mosquito bites. Seventy six percent of the respondents claimed children $<5$ years of age should be given priority to sleep under ITN in the household. Only few respondents, $1.63 \%$, considered pregnant women as priority groups to sleep under ITNs. Furthermore, about $63 \%$ of the respondents showed their willingness to buy ITNs if they are affordable. The responses by male and female household heads to most of the KAP questions were not significantly different $(\mathrm{P}>0.05)$. Out of the 260 nets inspected for usage and physical condition during the survey period, more than $50 \%$ were kept in a box or other container in the households. Nets that were graded as clean and very dirty accounted for $25 \%$ and $25.77 \%$, respectively. Physical inspection of the randomly sampled nets also revealed holes ranging from those that didn't allow a thumb to pass through $(\bar{X}$ number $=3.47)$ to those that were wider than a closed fist ( $\bar{X}$ number $=1.64$ ). The over all knowledge, attitude and practice of ITN usage was found to be satisfactory in the study district. However, the occupant net ratio must be narrowed and attention needs to be given to malaria vulnerable groups in the household. Continuous monitoring and evaluation of net usage after distribution should be instituted to avoid misuses and associated net damages in the study areas.
\end{abstract}

Key words: Malaria prevention, Insecticide treated nets, Tigray, Ethiopia

\section{INTRODUCTION}

Global incidence of malaria is estimated to be 250 million clinical cases annually leading to approximately 1 million deaths mostly of children under 5 years of age. Plasmodium falciparum causes most of the deaths in sub-Saharan Africa (WMR, 2008; WMR, 2005). Seventy five percent of the total landmass of Ethiopia is malarious and $68 \%$ of its population (48 million) is estimated to be at risk of malaria infection (WMR, 2008). Seventy five percent of Tigray regional State of Ethiopia is potentially malarious (Gehebreyesus et al., 1999). Kolla Tembien 
district is one of the malarious districts in Tigray regional state (Cropper et al., 2000). Since 1950's, significant efforts have been done to control malaria in Ethiopia. However, the disease continues to be one of the major causes of illness, death and impediment to socioeconomic development in the country (FMoH, 2006). The national Malaria Control Program (MCP) of Ethiopia developed a strategic plan to reduce the burden of the disease by 25\% in the year 2005 and by $50 \%$ in the year 2010 . To meet the above mentioned goal, early diagnosis and effective treatment, selective vector control and epidemic prevention and control has been the main focus (FMoH, 2006). On the contrary, both the chemotherapy and vector control arms of malaria prevention mainly through indoor residual insecticide spray (IRS) are being challenged by the appearance of drug resistance Plasmodium parasites and insecticide resistant Anopheles mosquito vectors, respectively in sub-Saharan Africa including Ethiopia (Schunk et al., 2006; Teka et al., 2008; Bloland, 2001; Balkew et al., 2003; Balkew et al. 2006). This together with unstable nature of malaria transmission in Ethiopia (Negash et al., 2004), necessitates high distribution of ITNs to malaria prone areas as one of the major vector control strategies.

Insecticide treated nets are reported to be highly effective in reducing childhood mortality and morbidity from malaria (Lengeler, 2004). In Ethiopia insecticidal net coverage has increased to 53.3\% (FMoH, 2008). Nation wide distribution of ITNs especially long lasting insecticide treated nets (LLITNs) along with artemisinin-based combination therapy (ACT) has resulted in $73 \%$ reduction in in-patient malaria cases as well as $62 \%$ reduction in deaths in children under 5 years of age in Ethiopia (Otten et al., 2009). Like other malarious areas of Ethiopia, insecticidal nets are among the major malaria vector control strategies in malaria prone areas of Tigray region. Out of 717, 813 malaria exposed households in the region, 533, 939 (74.4\%) households received at least one ITN (personal communication to representative of Malaria Department in Tigray Regional Health Bureau).

However, the success of ITNs depends on several factors such as, willingness of people to use nets, and behavior of the local vector(s) (WHO, 2006; Teklehaimanot et al., 2007).

Though, substantial increase has been reported regarding household insecticidal net ownership in Ethiopia, barriers ranging from house structure to user behavior are becoming obstacles for optimal use (NetMark, 2007). So far, there are limited data on knowledge, attitudes and practice of households about ITNs in malarious areas of Ethiopia in general and Tigray region in particular. Lack of knowledge regarding priority groups to sleep under ITNs in the household, 
believing ITNs to have negative side effects and inappropriate usage frequency are reported to hamper effective utilization of ITNs in different parts of Ethiopia (Dagne and Deressa, 2008; Animut et al., 2008; Fettene et al., 2009). However, only little is known about knowledge, attitude and practice of ITN usage at household level in malariaus areas of Tigray region in general and Kolla Tembein district in particular. Hence, this study was aimed at evaluating knowledge, attitude and practice (KAP) about ITNs at household level in rural sub-districts of Kolla Tembien district. This study also attempted to inspect the physical condition of ITNs owned by the randomly selected households in the study areas.

\section{METHODOLOGY}

\subsection{Study areas and population}

This study was carried out in four sub-districts of Kolla Tembien district in Tigray Region that are located at the periphery of Abiy-Adi town based on information on high prevalence of malaria in these areas (Hailemariam Alemayehu, personal communication). Moreover, Kolla Tembein district was selected for the current study because it is reported to be one of the highly malarious districts in the region that received large scale ITN distribution since the years 2005/2006 (personal communication to representative of Malaria Department in Tigray Regional Health Bureau). The population of the study sub-districts depends on subsistence farming for household food supply and income generation. 'Hidmo' (houses made up of stone wall and wooden roof covered with flat stones, mud, and thatch) account for the majority of houses in the study sub-districts while few houses were made of stone wall and iron roofs. In addition to indoor residual spraying (IRS) of houses with DDT or Malathion, ITNs have also been distributed to all malarious sub-districts by the district Health Bureau (Hailemariam Alemayehu, personal communication).The sub-districts involved in this study namely Bega Sheka, Getsekimlesley, Work Amba and Ataklti are different from each other with respect to altitude and geographical coordinates (Table 1).

\subsection{Study design and sampling technique}

The study sub-districts were selected based on their accessibility and proximity to the district capital, Abiy-Adi. Stratified, systematic random sampling was used for selection of a total of 368 households from all the four sub-districts. Decision on this sample size was made due to the budget and time limitations of the study. Close-ended interview questionnaire were first prepared 
in English and then translated into the local language, Tigrigna, for data collection. Upon arrival to each sub-district, the team of three interviewers dispersed in different directions and marked every other household until approximately 90 households per sub-district were interviewed.

Table 1. Location of the study sites with altitudes and geographical coordinates.

\begin{tabular}{|lllc|}
\hline $\begin{array}{l}\text { Name of the sub- } \\
\text { district }\end{array}$ & Altitiude (m.a.s.l.) & \multicolumn{2}{l|}{ Geographical coordinates } \\
\cline { 3 - 4 } & & North & East \\
\hline Bega Sheka & 1747 & $13^{0}$ & $038^{\circ} 55.734^{\prime}$ \\
& & $37.640^{\prime}$ & \\
\hline Getsekimlesley & 1840 & $13^{\circ}$ & $038^{0} 57.615^{\prime}$ \\
& & $38.345^{\prime}$ & \\
\hline Work Amba & 1885 & $13^{\circ}$ & $039^{\circ} 00.091^{\prime}$ \\
& & $43.895^{\prime}$ & \\
\hline Ataklti & 1992 & $13^{\circ}$ & $038^{\circ} 57.375^{\prime}$ \\
& & $41.031^{\prime}$ & \\
\hline
\end{tabular}

\subsection{Data collection and analysis}

Data were collected from March-May, 2010. The rationale to conduct the study during this period was that malaria occurs through out the year in the study sub-districts however, with low rate (Cropper et al., 2000); and the district Health Bureau is mobilizing community health workers to ensure continuous use of ITNs among the households. Therefore, this study was conducted during the abovementioned period to see the knowledge, attitude and practice of households on sustainable use of ITNs throughout the year in the sub-districts.

Interviews were administered to household heads or their representatives to collect data. Interview questionnaire contained variables such as characteristics of households, demographic information on the respondents and KAPs (knowledge on the role of ITNs in malaria prevention, mode of malaria prevention by ITNs, priority groups to sleep under ITNs in the family, when and where to use ITNs, other benefits of ITNs in the household and interest to buy ITNs if supplied). Observational check list containing variables such as net position, presence or absence of hole, presence or absence of repairs and general condition (cleanliness) were used for physical inspection of one ITN that was randomly selected from each of the net owning households. If present, holes were classified into three (1) holes that didn't allow a thumb to pass through; (2) holes that didn't allow a closed fist to pass through; and (3) holes that were wider than a closed fist. Cleanliness of nets was rated based on the type of spoiling dirt at least on one of the four surfaces. Consequently, nets in which at least one of the surfaces was stained with dust, soot and 
household liquid dirt were graded as very dirty; nets in which at least one of the surfaces spoiled with soot and dust were graded as dirty; nets in which at least one of the surfaces spoiled with only dust were graded as a bit dirty; and nets in which all the four surfaces were free from dust, soot and household liquid dirt were graded as clean. Data was analyzed using $\mathrm{X}^{2}$ tests. The analysis was carried out using SPSS version 10 (SPSS, Inc. USA).

\section{RESULTS}

\subsection{Characteristics of households}

A total of 368 households have been surveyed during the study period and out of these, 70.65\% were found to own at least one ITN. On the other hand, the mean number of individuals sleeping under one ITN and the mean number of total occupants in the households surveyed were found to be 3.13 and 5.50, respectively. Consequently, nearly half of the occupants in the households surveyed rely on a single ITN to prevent malaria transmission (Table. 2).

Table 2. Characteristics of households surveyed for insecticide treated nets (ITNs) usage in rural sub-districts of Kolla Tembein.

\begin{tabular}{|ll|}
\hline \multicolumn{2}{|c|}{ Variables } \\
\hline $\bar{X}$ Number of occupants $\pm(\mathrm{SD})$ & $5.50 \pm(1.9)$ \\
\hline $\bar{X}$ Number of ITNs received during previous distribution $\pm(\mathrm{SD})$ & $1.89 \pm(0.78)$ \\
\hline $\bar{X}$ Number of ITNs owned at present \pm (SD) & $1.07 \pm(0.90)$ \\
\hline $\bar{X}$ Number of individuals sleeping under one bed net \pm (SD) & $3.13 \pm(0.83)$ \\
\hline \% of households possessing at least one ITN & 70.65 \\
\hline \% of households without bed nets & 29.35 \\
\hline House types & 88.86 \\
\hline \% of ‘Hidmo' & 10.87 \\
\hline \% of stone wall and iron roof houses & \\
\hline
\end{tabular}

\subsection{Demographic information}

About 258 (70\%) of the household heads involved in the study were females. Majority of the respondents (89.40\%) are illiterate and live on subsistence small scale agriculture for household food supply and income generation. Large proportion of the respondents (41.07\%) fall in age categories between 35 and 39 years while about $60 \%$ of the remaining respondents fall in age categories younger or older than the aforementioned age range (Table 3).

\subsection{KAPs about ITNs}


Knowledge, attitude and practices with regard to ITN use is summarized in table 4. Concerning knowledge of household heads about the role ITNs, $82.34 \%$ of respondents reported that they use the nets for protection from mosquito bites. Only $1.09 \%$ of the respondents claimed ITNs to protect them from malaria, the disease. More than fifty seven percent of the interviewees have also reported that they sleep under ITNs every night. Regarding groups who are given priority to sleep under ITNs in the household, 76.63\% of the respondents indicated children bellow five years of age to be given priority. While $12.23 \%, 3.80 \%$ and $1.63 \%$ of the respondents believed priority should be given to whole family, old family members and pregnant women, respectively. Furthermore, a total of $63.04 \%$ of the interviewees had positive attitude towards buying ITNs if supplied by some body or organization with an affordable price while the rest of the respondents, $36.96 \%$, preferred free distribution by the government.

Table 3. Demographic information on respondents in rural sub-districts of Kolla Tembein. (Note: * includes of traditional gold mining in the study area).

\begin{tabular}{|c|c|}
\hline Variables $(n=368)$ & No. (\%) \\
\hline \multicolumn{2}{|l|}{ Age range in years } \\
\hline $15-19$ & $08(2.17)$ \\
\hline $20-24$ & $18(4.89)$ \\
\hline $25-29$ & 38 (10.33) \\
\hline $30-34$ & 42 (11.41) \\
\hline $35-39$ & 69 (41.07) \\
\hline $40-44$ & 32 (8.69) \\
\hline $45-49$ & $31(8.42)$ \\
\hline $50-54$ & $46(12.50)$ \\
\hline 55-59 & $21(5.71)$ \\
\hline $60-64$ & $36(9.78)$ \\
\hline 65-69 & $11(2.99)$ \\
\hline $70-74$ & $09(2.44)$ \\
\hline $75-79$ & $04(1.09)$ \\
\hline $80-84$ & $03(0.81)$ \\
\hline \multicolumn{2}{|l|}{ Sex } \\
\hline Female & $258(70.10)$ \\
\hline Male & 110 (29.89) \\
\hline \multicolumn{2}{|l|}{ Education } \\
\hline Illiterate & $239(89.40)$ \\
\hline 1-6 grades & $30(8.15)$ \\
\hline 7-8 grades & $05(1.36)$ \\
\hline$>8$ grade & 04 (1.09) \\
\hline \multicolumn{2}{|l|}{ Occupation } \\
\hline Small scale & 365 (99.18) \\
\hline
\end{tabular}




\begin{tabular}{|l|}
\hline agriculture \\
\hline Others $^{*}$ \\
\hline
\end{tabular}

Table 4. Knowledge and attitudes of household heads about ITN usage in rural sub-districts of Kolla Tembein.

\begin{tabular}{|c|c|c|c|}
\hline Variables $(n=368)$ & No. $(\%)$ & Variables $(n=368)$ & No. $(\%)$ \\
\hline \multicolumn{2}{|c|}{ ITNs prevent malaria transmission } & \multicolumn{2}{|l|}{ Preference on the type of ITN } \\
\hline Agree & 359 (97.55 & None treated nets & 06 (1.63) \\
\hline Disagree & $09(2.44)$ & Conventional ITNs & $159(43.21)$ \\
\hline Do not know & $02(0.54)$ & LLITNs & $144(39.13)$ \\
\hline \multicolumn{2}{|c|}{ Mode of malaria prevention by ITNs } & No idea & $59(16.03)$ \\
\hline By avoiding mosquito bites & $303(82.34)$ & ITN usage & \\
\hline By avoiding any insect bite & $55(14.94)$ & Difficult & $17(4.62)$ \\
\hline By avoiding malaria & $04(1.09)$ & Easy & $344(93.48)$ \\
\hline By avoiding dust and dirt & $01(0.27)$ & No idea & $07(1.90)$ \\
\hline By other means & $04(1.09)$ & $\begin{array}{l}\text { Side effects associated with } \\
\text { ITN utilization }\end{array}$ & \\
\hline Do not know & $01(0.27)$ & No side effects & $322(87.50)$ \\
\hline \multicolumn{2}{|c|}{$\begin{array}{l}\text { Priority groups to sleep under ITNs in the } \\
\text { households }\end{array}$} & Minor side effects & $35(9.51)$ \\
\hline Children $<5$ years of age & $282(76.63)$ & Do not know & $11(2.99)$ \\
\hline \multicolumn{2}{|l|}{ Adults with ages $>18$ years } & \multicolumn{2}{|l|}{$\begin{array}{l}\text { Factors that damage ITNs in } \\
\text { the household }\end{array}$} \\
\hline Pregnant women & $06(1.63)$ & $\begin{array}{l}\text { Long exposure to sun while } \\
\text { drying after washing }\end{array}$ & $51(13.86)$ \\
\hline Old (aged) family members & $14(3.80)$ & Dust and dirt & $17(4.62)$ \\
\hline Guests & $02(0.54)$ & Inappropriate handling & $229(62.23)$ \\
\hline $\begin{array}{l}\text { Equal priority for all family } \\
\text { members }\end{array}$ & $45(12.23)$ & $\begin{array}{l}\text { Rats and other domestic } \\
\text { animals }\end{array}$ & $22(5.98)$ \\
\hline Others & $14(3.80)$ & Fire & $03(0.81)$ \\
\hline Do not know & $02(0.54)$ & $\begin{array}{l}\text { Using bed nets for other } \\
\text { purposes }\end{array}$ & $11(2.99)$ \\
\hline \multicolumn{2}{|c|}{ Frequency of ITN use by households } & Frequent washing & $15(4.08)$ \\
\hline Every night & $211(57.34)$ & Do not know & $20(5.43)$ \\
\hline Sometimes & $11(2.99)$ & Other benefits of ITNs & \\
\hline During transmission season & $143(38.86)$ & Avoid dust, fleas and bed bugs & $154(41.85)$ \\
\hline Other times & $04(1.09)$ & Do not know & $214(58.15)$ \\
\hline \multicolumn{2}{|c|}{ Rooms where ITNs are used in the house } & \multicolumn{2}{|l|}{ Willingness to buy ITNs } \\
\hline Living room & $09(2.44)$ & Yes & $232(63.04)$ \\
\hline $\begin{array}{l}\text { Where there is mud sleeping } \\
\text { surface/ bed in the house }\end{array}$ & $355(96.45)$ & No & $136(36.96)$ \\
\hline Kitichen & 04 (1.09) & & \\
\hline
\end{tabular}

\subsection{Physical status and usage of nets inspected}

Out of 260 nets observed during the survey period, 52.31\% were kept in a box or other container. Besides, $3.46 \%$ of the nets observed were used as a cover on mud sleeping surfaces in the 
household. Only $12.31 \%$ of the nets observed were found to be hanging and ready for use. More than $30 \%$ of the nets observed were graded as a bit dirty while the proportions of nets graded as clean and very dirty were $25 \%$ and $25.77 \%$, respectively (Table 5).

Table 5. Physical conditions of a randomly selected insecticide treated nets (ITNs) from households that own at least one net with respect to usage and cleanliness in rural subdistricts of Kolla Tembein.

\begin{tabular}{|lc|}
\hline Variable (n=260) & No. (\%) \\
\hline Net usage & \\
\hline Nets stored in a box or other container & $136(52.31)$ \\
\hline Nets hanging and ready for use & $32(12.31)$ \\
\hline Nets as cover of mud sleeping surfaces & $9(3.46)$ \\
\hline Nets at other position & $83(31.92)$ \\
\hline Cleanness & \\
\hline Clean nets & $65(25)$ \\
\hline A bit dirty nets & $79(30.38)$ \\
\hline Dirty nets & $49(18.85)$ \\
\hline Very dirty nets & $67(25.77)$ \\
\hline
\end{tabular}

Holes ranging form those that didn't allow a thumb to pass through $(\bar{X}$ number $=3.47)$ to those that were wider than a closed fist $(\bar{X}$ number $=1.64)$ were detected on nets inspected suggesting the range of physical damage of the nets. Stitches were the most commonly observed types of repairs ( $\bar{X}$ number $=0.27$ ) where as very few nets $(\bar{X}$ number $=0.004)$ were observed to be repaired with patches (Table. 6).

\section{DISCUSSION}

There was no significant difference among the responses provided by the different age groups of the interviewees to KAP variables including knowledge on the role of ITNs in malaria prevention, mode of malaria prevention by ITNs, priority groups to sleep under ITNs in the family, when and where to use ITNs, other benefits of ITNs in the household and interest to buy ITNs if supplied $(\mathrm{P}>0.05)$. Similarly, the responses provided by male and female household heads to KAP variables including knowledge on the role of ITNs in malaria prevention, mode of malaria prevention by ITNs, priority groups to sleep under ITNs in the family, when and where to use ITNs, other benefits of ITNs in the household and interest to buy ITNs if supplied were not significantly different $(\mathrm{P}>0.05)$. 
Table 6. Physical conditions of a randomly selected insecticide treated nets (ITNs) from households that own at least one net with respect to type and number of holes and repairs in rural sub-districts of Kolla Tembein.

\begin{tabular}{|ll|}
\hline Variable (n=260) & $\bar{X} \pm($ SD) \\
\hline Holes & \\
\hline That didn't allow a thumb to pass through & $3.47 \pm(6.25)$ \\
\hline That didn't allow a closed fist to pass through & $1.55 \pm(2.71)$ \\
\hline Wider than a closed fist & $1.64 \pm(1.96)$ \\
\hline Repairs & \\
\hline Stitches & $0.27 \pm(1.16)$ \\
\hline Knots & $0.06 \pm(0.36)$ \\
\hline Patches & $0.004 \pm(0.06)$ \\
\hline
\end{tabular}

However, physical inspection of a randomly selected ITN from each of the study households identified nets with poor cleanliness, holes and inappropriately placed in the houses surveyed. On the other hand, the imbalance between the number of occupants and number of ITNs owned per household can hamper its effective utilization.

Awareness of the study subjects to associate mode of malaria prevention by ITNs via protection from mosquito bites is much higher (82.34\%) in the present study but lower (51.4\%) in a similar study carried out in other parts of Tigray, Mereb Lake and Tselemti (Animut et al., 2008). Most of the interviewees in this study (57.34\%) claimed ITNs to be used by the household every night. Previous studies have also reported similar frequency of ITNs use by rural and urban households in different parts of Ethiopia including Tigray (Jima et al., 2005 Fettene et al., 2009; Animut et al., 2008). Most (57.34\%) of the households claimed to use ITNs every night throughout the year. This frequency of ITNs use might be ensured due to continuous health education provided by community health workers in the study sub- districts. Furthermore, in the present study household heads (38.86\%) indicated malaria transmission seasons to be the second important periods when ITNs are used in higher frequency. However, in Mereb Lake and Tselemti few household heads (4.7\%) reported lower frequency of ITNs use during transmission seasons (Animut et al., 2008).

Most of the interviewees (76.63\%) involved in this study identified children bellow five years age to be the priority groups to sleep under ITNs in their household. On the other hand, very few respondents (1.63\%) perceived pregnant women as a priority group to sleep under ITNs. These 
results are consistent with the findings of Animut et al (2008) from Mereb Lake and Tselemti. The results of both of these studies suggest adequate knowledge among respondents regarding the vulnerability of children less than five years of age to malaria. However, the respondents in both of these studies didn't have sufficient knowledge regarding vulnerability of pregnant women to malaria in terms of prioritizing them for ITN use in the household.

This study revealed most of the people in the sub-districts (93.7\%) to have appropriate knowledge regarding ITNs use. However, actual inspection of ITNs has shown difficulties in net usage such as hanging of nets on the wall without using it and keeping them in their packages. Most of the ITNs inspected were not hanged appropriately. This may be due to the fact that the rectangular net occupies most of the spaces in the house; nails used to hang the nets cannot pierce the stone wall of the traditional 'hidimo' houses and sleeping surfaces made of mud are narrow and have no space to tuck the nets in.

About $42 \%$ of the interviewees in the present study pointed out protection from dust, fleas and bed bugs to be among additional benefits they obtain from ITNs. Such additional benefits may have positive impact on the frequency of ITN use by the households. However, from the observational component of the present study, it was possible to identify households that misuse ITNs in an attempt to get any one of the aforementioned benefits. During the survey period it was not uncommon to observe households misusing ITNs as bed sheets and covers of bed, mattres, or mat. Such misuses of ITNs were also reported by a study conducted in Oromia and Amhara regions, Ethiopia (NetMark, 2007). Similarly, misuse of ITNs for fishing and drying fish was reported from fishing communities living adjacent to Lake Victoria, Kenya (Minakawa et al., 2008). Furthermore, nearly all of the respondents in this study (99.18\%) are engaged in subsistence small scale agriculture and are observed to misuse ITNs as a cover of harvested crops and for sun drying crop grains.

Most of the household heads (87.50\%) reported absence of negative side effects associated with the use of ITNs except few respondents who claimed minor side effects such as skin rash in young children. Furthermore, majority of the interviewees (63.04\%) have interest to purchase ITNs in cash if they are provided with an affordable price. This result is consistent with the finding of Jimma et al. (2005) in urban kebeles of Southern Nations Nationalities and Peoples Region (SNNPR), Oromia and Amhara Regional States. 
Physical inspection of randomly selected ITNs has shown that more than $50 \%$ of the ITNs inspected were not hanged as bed nets but stored in a box or other containers. Some households were found to have new ITN with unopened package. One of the major reasons claimed by some of the household heads regarding storing nets in a container was to save the nets for future use as there was no recent distribution. Pervious study by NetMark (2007), also confirmed similar findings.

This study rated the nets inspected into very dirty, dirty, a bit dirty and clean based on the type of spoilage dirt on at least one of its surfaces. In this regard about $25 \%$ of the nets inspected were rated dirty because of spoilage of at least one of its surfaces with dust, soot and household liquid dirt. The type of spoilage on at least one of the surfaces of the nets may be due to poor handling by the households. Nets observed in households that do not have separate Kitichen were highly spoiled with soot. Mud plastered roof of the traditional 'hidmo' house and misuse of nets for agricultural activities such as drying grains and covering harvested crops and cattle feed (hay) may be responsible for spoilage of the nets with dust in the study areas. On the other hand, using nets to filter drinking water, boiled butter or oil in the households might render them to be stained with liquid dirt. All the above spoilage factors may play their role in reducing the efficacy of ITNs against mosquito vectors as indicated by Fettene et al., 2009.

In this study variables such as presence and type of holes, presence and type of repairs and overall cleanliness of the nets inspected were also used as parameters to determine the level of damage. Holes are also used in a pervious study by Fettene et al. (2009) to determine the level of net damage. However, these authors didn't classify holes into different categories based on their diameter. Abrasions resulting from poor net handling might be responsible for the holes identified in this study. In households that do not have kitchen, fire might also contribute its part to create holes of different sizes on net surfaces.

\section{CONCLUSION AND RECOMMENDATIONS}

The present study evaluated the overall knowledge, attitudes and practices of insecticide treated mosquito net (ITN) usage to be satisfactory among the study subjects however; most of the respondents in the study area gave no priority to pregnant women to sleep under ITNs. On the other hand, there was imbalance between family size and number of ITNs owned by the households. Physical inspection of nets sampled from net owning households revealed misuses 
and ITN damages. Therefore, awareness creation regarding proper use of ITNs is necessary. There is also a need for implementation of continuous monitoring and evaluation of usage after ITN distribution in-line with prioritizing vulnerable groups of the population, children and pregnant women. Furthermore, ITN manufacturers must consider house types in which the nets are used as 'one size fits all' doesn't work for ITN under housing conditions in the study area.

\section{ACKNOWLEDGEMENTS}

This study received financial support from the College of Natural and Computational Sciences (CNCS), Mekelle University. The regional and Kolla Tembien district Health Bureaus as well as representatives of the sub-districts are highly acknowledged for facilitating the study. We are grateful to Mr. Solomon Tesfay and Mr. Solomon Amare, Technical Assistants in the Department of Biology, Mekelle University for their help during field data collection.

\section{REFERENCES}

Animut, A., Gebre-Michael, T., Medhin, G., Balkew, M., Bashaye, S \& Seyoum, A. 2008. Ethiopian Journal of Health Development, 22: 268-274.

Balkew, M., Gebre-Michael, T \& Hailu, A. 2003. Insecticide susceptibility level of Anopheles arabiensis in two agro development localities in eastern Ethiopia. Parasitologia, 45: 1-3.

Balkew, M., Elhassen, I., Ibrahim, M., Gebre-Michael, T \& Engers, H. 2006. Very high DDTresistant population of Anopheles pharoensis Theobald (Diptera: Culicidae) from Gorgora, northern Ethiopia. Parasite, 13: 327-329.

Bloland, P. B. 2001. Drug resistance in malaria. World Health Organization (WHO), WHO/CDS/CSR/DRS/2001.4.

Cropper, M. L., Haile, M., Lampietti, J. A., Poulos, C \& Whittington, D. The value of preventing malaria in Tembien Ethiopia. The World Bank, 1818 H. Street, Washington, DC, 20433, report.

Dagne, G \& Deressa, W. 2008. Knowledge and utilization of insecticide treated mosquito nets among freely supplied households in Wonago Woreda, Southern Ethiopia. Ethiopian Journal of Health Development, 22:34-41. 
Fettene, M., Balkew, M \& Gimblet, C. 2009. Utilization, retention and bio-efficacy studies of PermaNet ${ }^{\circledR}$ in selected villages in Buie and Fentalie districts of Ethiopia. Malaria Journal, 8:114.

FMoH. 2006. National five-year strategic plan for malaria prevention and control in Ethiopia 2006-2007 report. Ministry of Health, Addis Ababa, Ethiopia

FMoH. 2008. Ethiopia national malaria indicator survey 2007: technical summary report Addis Ababa, Ethiopia.

Gehebreyesus, T. A., Witten, K. H., Getachew, A, O’Neill, K., Bosman, A \& Teklehimanot, A. 1999. Community-based malaria control in Tigray, Northern Ethiopia. Parasitologia, 41: 367-371.

Jima, D., Tesfaye, G., Deressa, W., Woyessa, A., Kebede, D \& Alemirew, D. 2005. Baseline survey for the implementation of insecticide treated mosquito nets in Malaria control in Ethiopia. Ethiopian Journal of Health Development, 19: 16-23.

Lengeler, C. 2004. Insecticide-treated bed nets and curtains for preventing malaria. Cochrane Database of Systematic Reviews 2004, Issue 2. Art. No.:CD000363. DOI: 10.1002 14651858. CD000363 pub2.

Minakawa, N., O Dida, G., O Sonye, G., Futami, K \& Kaneko, S. 2008. Unforeseen misuses of bed nets in fishing villages along Lake Victoria. Malaria Journal, 7:165.

Negash, K., Jima, D., Nafo-Traore, F., et al. (2004). Ethiopia roll back malaria consultative mission: essential actions to support the attainment of the Abuja targets. Ethiopia RBM Country Consultative Mission Final Report, Addis Ababa, Ethiopia. 39pp.

Net Mark, 2007. Ethiopia Bed net utilization study: why some nets owned are not used. A project at AED funded by the United States Agency for International Development under Cooperative Agreement No.HRN-A-00-99-00016-00. 22pp.

Otten, M., Aregawi, M., Were, W., Karema, C., Medin, A., Bekele, W., Jima, D., Gausi, K., Komatsu, R., Korenromp, E., Low-Beer, D \& Grabowsky, M. 2009. Initial evidence of reduction of malaria cases and deaths in Rwanda and Ethiopia due to rapid scale-up of malaria prevention and treatment. Malaria Journal, 8: 1-8.

Schunk, M., Kumma, W., P., Osman, I., B., M., Roewer, S., Alano, A., Loscher, T \& Mockenhaupt, F., P. 2006. High prevalence of drug-resistance mutations in Plasmodium falciparum and Plasmodium vivax in southern Ethiopia. Malaria Journal. 5: 1-8. 
Teka, H., Petros, B., Yamuah, L., Tesfaye, G., Elhassan, I., Muchohi, S., Kokwaro, G., Aseffa, A \& Engers, H. 2008. Chloroquine-resistant Plasmodium vivax malaria in Debre Zeit, Ethiopia. Malaria Journal, 7: 1-8.

Teklehaimanot, A., Sachs, J.D \& Curtis, C. 2007. Malaria control needs mass distribution of insecticidal bednets. Published online June 21, DOI: 10.1016/S0140-6736(07) 60951-9.

WHO. 2006. Malaria vector control and personal protection. World Health Organization Technical Report Series no. 936. Geneva.

WMR. 2005. WHO/HTM/MAL/2005.1102.

WMR. 2008. World Malaria Report. WHO/HTM/GMP/2008.1, World Health Organization, Geneva. 